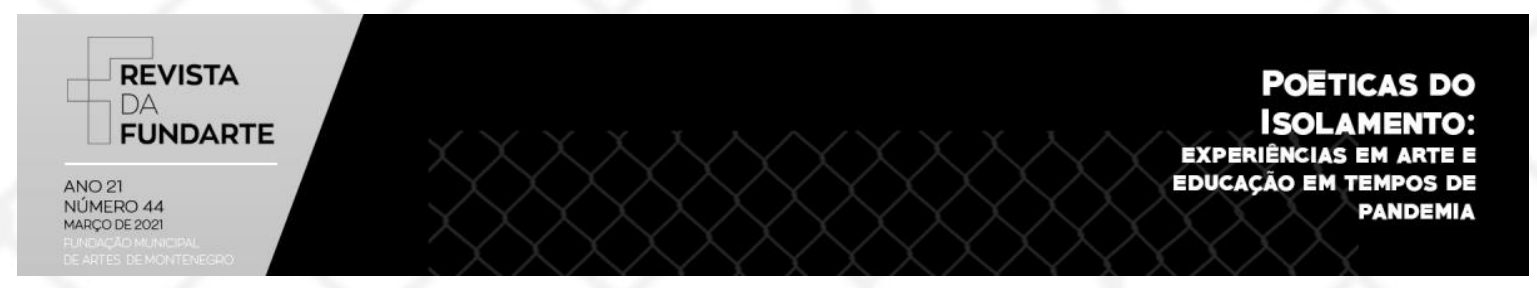

\title{
AULAS DE TROMPETE VIRTUAIS EM MEIO À PANDEMIA DA COVID-19 NO PROJETO ORQUESTRA JOVEM DO RIO GRANDE DO SUL: UM RELATO DE EXPERIÊNCIA
}

Resumo: Trago neste texto, um relato de experiência relacionado às atividades e aulas de trompete que ocorreram durante a pandemia da Covid-19 no projeto Orquestra Jovem do Rio Grande do Sul ${ }^{2}$ no período de 01 de março a 17 de dezembro de 2020.

Palavras chaves: Orquestra jovem; Trompete; Pandemia.

\section{VIRTUAL TRUMPET LESSONS AMID THE COVID-19 ON-PROJECT PANDEMIC ORQUESTRA JOVEM DO RIO GRANDE DO SUL: AN EXPERIENCE REPORT}

\begin{abstract}
I bring in this text, an experience report related to the activities and trumpet classes that occurred during the Covid-19 pandemic in the Orquestra Jovem do Rio Grande do Sul project from March 1st to December 17th, 2020.
\end{abstract}

Key words: Youth orchestra; Trumpet; Pandemic.

\section{Introdução}

No início da pandemia da covid-19 diversas instituições de ensino tiveram suas atividades paralisadas abruptamente, fazendo com que muitas tivessem que se adaptar as normas da Organização Mundial da Saúde (OMS) para que continuassem funcionando. Com o projeto Orquestra Jovem do Rio Grande do Sul não foi diferente, a coordenação e professores tiveram que repensar a forma de

\footnotetext{
1 Isac Costa Soares é mestrando em educação musical pela Universidade Federal do Rio Grande do Sul - UFRGS, licenciado em música pelo Centro Universitário Metodista IPA e formou-se em trompete/performance na Escola de Música da OSPA. Atua como professor no Projeto Ouviravida, Orquestra Jovem do Rio Grande do Sul e como trompetista na Orquestra de Sopros de Novo Hamburgo, além de integrar o Grupo de Pesquisa Educação Musical e Cotidiano EMCO.

2 A Orquestra Jovem do Rio Grande do Sul foi criada em 2009, seguindo uma tendência internacional de criação de Orquestras Jovens na América Latina, com foco na formação musical de excelência, e voltada prioritariamente para o atendimento de crianças e adolescentes de famílias de baixa renda e integrantes da rede escolar, dos 10 aos 24 anos. Fonte: http://orquestrajovemrs.com.br/ Acesso: $06 / 01 / 2021$
}

SOARES, Isac Costa. Aulas de trompete virtuais em meio à pandemia da covid-19 no projeto orquestra jovem do Rio Grande do Sul: um relato de experiência. Revista da FUNDARTE. Montenegro, p.01-16, ano 21, o 44, janeiro/março de 2021.

Disponível em: http://.seer.fundarte.rs.gov.br/index.php/revistadafundarte/index> 30 de março de 2021. 


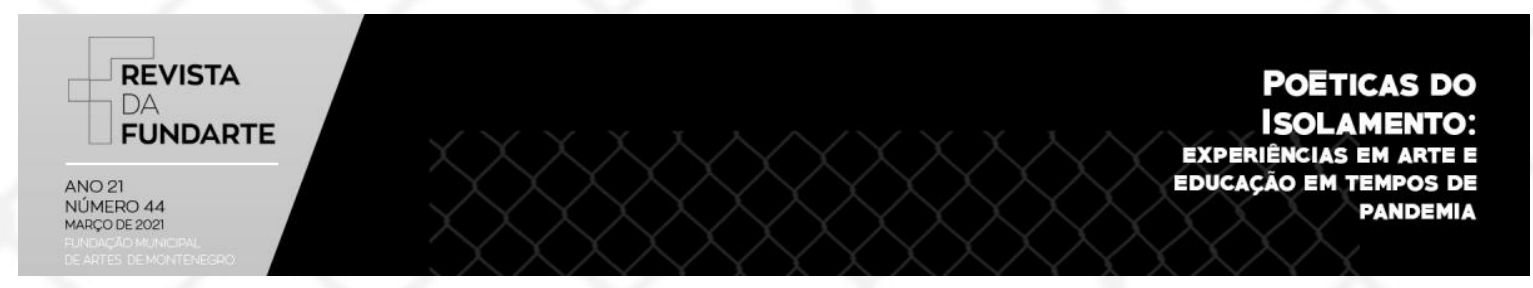

abordagem de ensino, uma vez que, mesmo as aulas sendo individuais, os ensaios eram sempre de forma coletiva e com um grande número de alunos.

Nas aulas de trompete tivemos alguns percalços pelo meio do caminho, mas também resultados positivos. Como professor, precisei repensar minhas práticas de ensino, tentando na medida do possível compreender o chamado "novo normal" que começamos a viver. Sendo assim, esse texto tem como objetivo compartilhar os desafios e reações advindas que o projeto precisou enfrentar, assim como questões enfrentadas durante as aulas de trompete nesse momento tão complexo que vivemos. O relato inicia mostrando o contexto local onde o projeto Orquestra Jovem do Rio Grande do Sul está inserido, seguido de uma contextualização sobre o tema, apresentando de forma breve questões sobre o funcionamento do projeto, depois descreve as formas de organização que precisaram ser feitas para manter o trabalho, a seguir relata como foram às aulas de trompete e, por fim, traz algumas considerações sobre as temáticas apresentadas.

\section{O Contexto local}

A partir de minha pesquisa de mestrado que está em andamento intitulada "Trajetória Formativa de Trompetistas Atuantes no Cenário Musical de Porto Alegre", onde busco compreender como ocorreu o processo de formação dos trompetistas entrevistados, fiz um breve levantamento utilizando sites, redes sociais e matérias em mídia dos projetos sociais existentes na cidade de Porto Alegre/RS, que oferecem ensino de trompete. Baseado nisso, mapeei outros projetos na intenção de compreender que tipo de aulas de música era ofertado nesses espaços e em que bairros eles estavam localizados. Na tabela, podemos notar que existe um número razoável de projetos que oferecem ensino de música com prática de orquestra.

SOARES, Isac Costa. Aulas de trompete virtuais em meio à pandemia da covid-19 no projeto orquestra jovem do Rio Grande do Sul: um relato de experiência. Revista da FUNDARTE. Montenegro, p.01-16, ano 21, no 44, janeiro/março de 2021.

Disponível em: http://.seer.fundarte.rs.gov.br/index.php/revistadafundarte/index> 30 de março de 2021. 


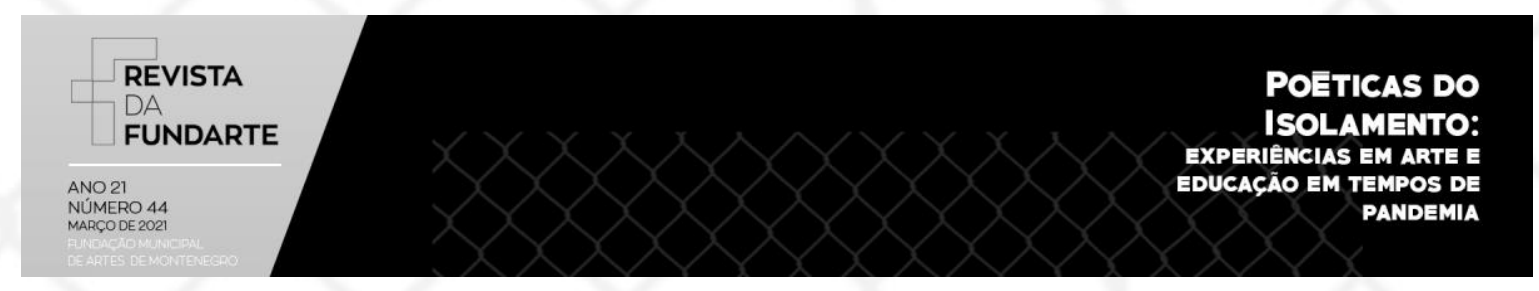

\begin{tabular}{|c|c|c|}
\hline Nome & $\begin{array}{l}\text { Instrumentos } \\
\text { Ofertados }\end{array}$ & Bairro \\
\hline Projeto Ouviravida & $\begin{array}{l}\text { Aulas de Flauta doce, } \\
\text { Canto coral, Percussão, } \\
\text { trompete, flauta } \\
\text { transversal, acordeom, } \\
\text { teclado e violão. }\end{array}$ & Bom Jesus \\
\hline $\begin{array}{l}\text { Orquestra Jovem do Rio } \\
\text { Grande do Sul }\end{array}$ & $\begin{array}{l}\text { Aulas de instrumento de } \\
\text { cordas, madeiras e metais } \\
\text { de orquestra e } \\
\text { musicalização. }\end{array}$ & Cidade Baixa \\
\hline CESMAR & $\begin{array}{l}\text { Banda Marcial, } \\
\text { musicalização e } \\
\text { Percussão. }\end{array}$ & Rubem Berta \\
\hline ONG Sol Maior & $\begin{array}{l}\text { Violão, cavaquinho, } \\
\text { bandolim, teclado, flauta, } \\
\text { percussão, bateria e canto } \\
\text { coral. }\end{array}$ & istórico \\
\hline AACAMUS & $\begin{array}{l}\text { Instrumentos de corda de } \\
\text { Orquestra, flauta doce, } \\
\text { cavaquinho e grupo vocal. }\end{array}$ & Independência \\
\hline IPDAE & $\begin{array}{l}\text { Instrumentos de cordas de } \\
\text { orquestra, flauta doce, } \\
\text { canto coral e piano. }\end{array}$ & Lomba do Pinheiro \\
\hline Orquestra Villa Lobos & $\begin{array}{l}\text { Instrumentos de corda de } \\
\text { orquestra, percussão, } \\
\text { flauta doce, violão, teclado } \\
\text { e canto coral. }\end{array}$ & Vila Mapa \\
\hline Associação Beneficente & Instrumentos de corda de & Partenon \\
\hline
\end{tabular}

SOARES, Isac Costa. Aulas de trompete virtuais em meio à pandemia da covid-19 no projeto orquestra jovem do Rio Grande do Sul: um relato de experiência. Revista da FUNDARTE. Montenegro, p.01-16, ano 21, no 44, janeiro/março de 2021.

Disponível em: http://.seer.fundarte.rs.gov.br/index.php/revistadafundarte/index> 30 de março de 2021. 


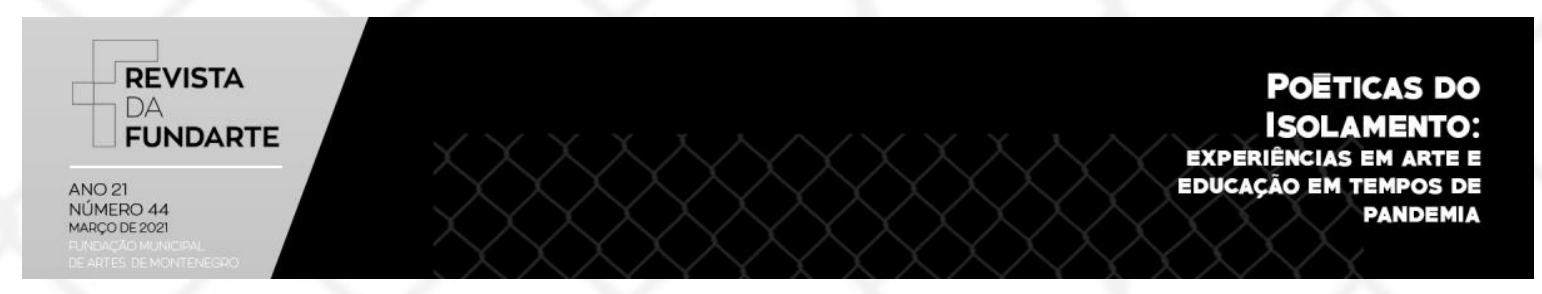

\begin{tabular}{|l|l|l|}
\hline Santa Zita de Lucca & $\begin{array}{l}\text { orquestra, flauta doce, } \\
\text { flauta } \\
\text { percussão e canto coral }\end{array}$ & \\
\hline Orquestra São Francisco & $\begin{array}{l}\text { Instrumentos de corda de } \\
\text { orquestra, flauta doce e } \\
\text { percussão. }\end{array}$ & Lomba do Pinheiro \\
\hline Educando com arte & $\begin{array}{l}\text { Instrumentos de corda de } \\
\text { orquestra, flauta doce e } \\
\text { percussão. }\end{array}$ & Tristeza \\
\hline
\end{tabular}

Figura 1 - Organizado pelo autor

Nota-se que a grande maioria desses projetos sociais trabalha com ensino de flauta doce, percussão, canto coral e instrumentos de corda de orquestra ${ }^{3}$. Os dois únicos projetos encontrados que ensinam instrumentos da família dos metais e tem ensino de trompete foram a Orquestra Jovem do Rio Grande do Sul e o Projeto Ouviravida. Um localizado na região central e outro em uma região periférica de Porto Alegre. No CESMAR há uma banda marcial, porém, não encontrei nada que falasse sobre ensino de instrumentos de metais ou trompete no site e na página do Facebook da instituição. Neste mapa, podemos perceber a distância que há entre eles, além de observamos a localização de cada projeto:

\footnotetext{
3 Utilizei o termo "corda de orquestra" para se referir aos seguintes instrumentos: violino, viola, violoncelo e contrabaixo.
}

SOARES, Isac Costa. Aulas de trompete virtuais em meio à pandemia da covid-19 no projeto orquestra jovem do Rio Grande do Sul: um relato de experiência. Revista da FUNDARTE. Montenegro, p.01-16, ano 21, o 44, janeiro/março de 2021.

Disponível em: http://.seer.fundarte.rs.gov.br/index.php/revistadafundarte/index> 30 de março de 2021. 

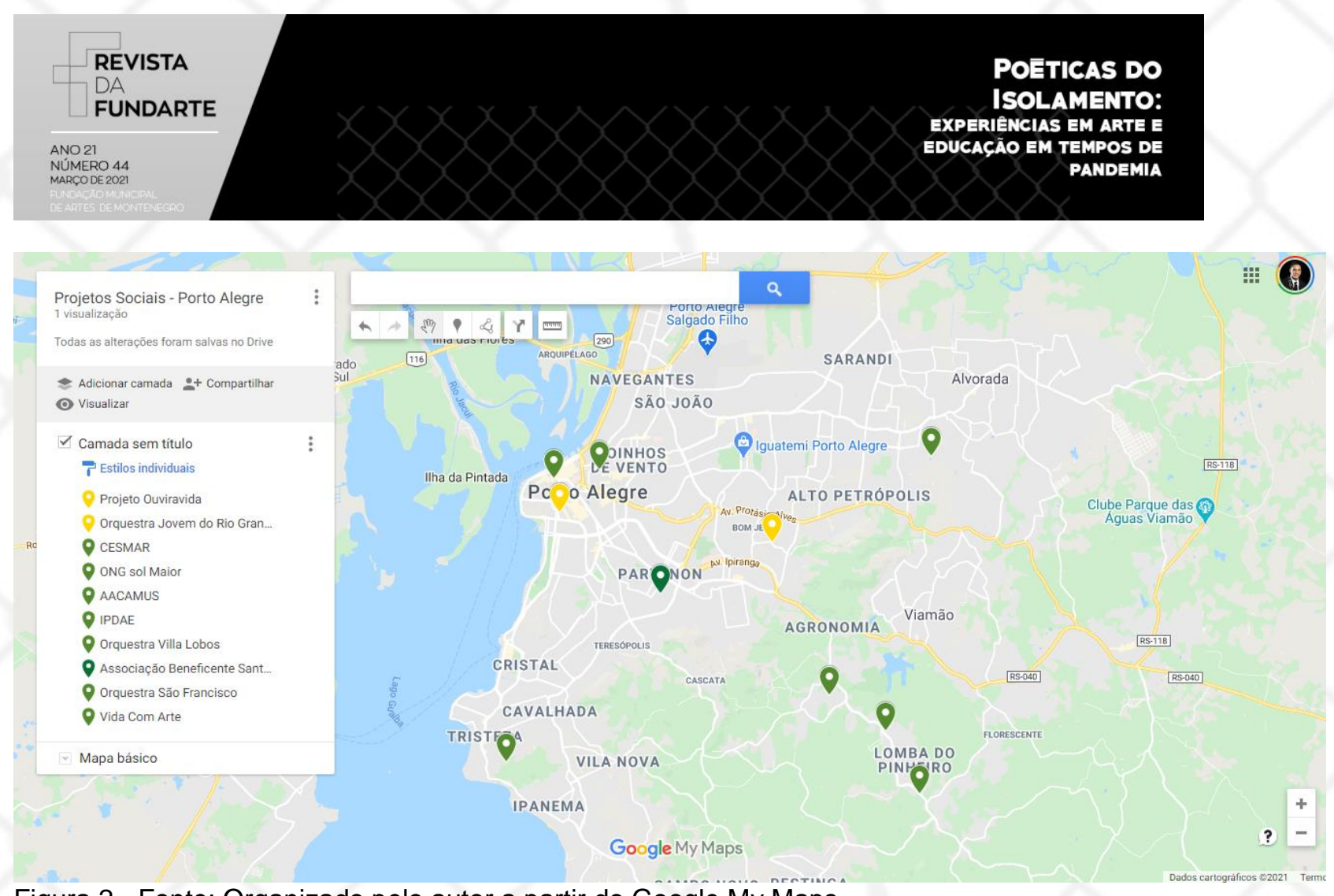

Figura 2 - Fonte: Organizado pelo autor a partir do Google My Maps

Sabendo-se da importância desses projetos na democratização do ensino de música, é visível que o ensino de trompete ainda é pouco aderido por essas instituições na cidade de Porto Alegre. Nesse sentido, este relato poderá contribuir mostrando como o projeto conseguiu manter-se em meio à pandemia e como as aulas e alunos de trompete vivenciaram esse período.

\section{Contextualização do tema}

Ao longo dos anos, diversos trabalhos têm surgido sobre o ensino de música em projetos sociais no Brasil. Nota-se isso, pela quantidade de pesquisas, artigos e relatos de experiência em revistas especializadas da área. Souza (2014) explica que esses projetos:

[...] são destinados a pessoas que são excluídas ou "menos visíveis" para a sociedade, como pessoas idosas, jovens, crianças, mulheres, negros, integrantes da comunidade LGBT, trazendo as questões de gênero, raça, geração, entre outras. Assim, as concepções pedagógicas presentes nos projetos sociais passam a considerar a diversidade e a heterogeneidade como regra e não como exceção. (SOUZA, 2014, p. 6).

SOARES, Isac Costa. Aulas de trompete virtuais em meio à pandemia da covid-19 no projeto orquestra jovem do Rio Grande do Sul: um relato de experiência. Revista da FUNDARTE. Montenegro, p.01-16, ano 21, no 44, janeiro/março de 2021.

Disponível em: http://.seer.fundarte.rs.gov.br/index.php/revistadafundarte/index> 30 de março de 2021. 


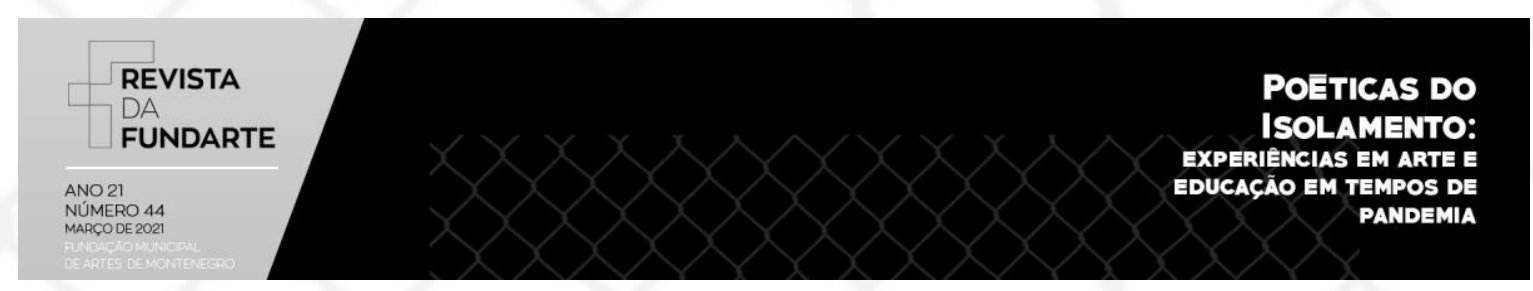

Em uma breve pesquisa no Portal de periódicos da Capes, foram encontrados $1.078^{4}$ artigos relacionados ao tema "música e projeto social". Isso demonstra o grande interesse de pesquisadores sobre o assunto. Autores como Souza (2014), Kater (2004), Bozzetto (2012), trazem reflexões importantes de como esses projetos de ação social funcionam e como acontecem as aulas de música nesses espaços. Essas pesquisas têm contribuído para uma percepção mais aprofundada sobre o tema, pois tratam de mostrar a diversidade de formas de ensino e aprendizagem de música nesses locais.

No que se refere aos projetos sociais com orquestra, Tramonte; Grubisic (2012) explicam que

[...] esses projetos têm atuado junto a um grande número de estudantes que não poderiam arcar com os custos de aprendizado musical seja de executar um instrumento em particular ou com a intenção de integrar-se em uma orquestra. (TRAMONTE; GRUBISIC, 2012, p. 290).

Nesse sentido, nota-se o importante papel que esses projetos têm na democratização do ensino de música, além disso, oportunizam a prática coletiva de instrumento, visto que, para fazer música orquestral é necessário tocar em conjunto. Sobre essa ótica, Santos et al. (2016) fundamentado em Tourinho (2008) coloca que:

[...] a educação musical coletiva estimula a permuta de experiências entre os alunos mais iniciantes e aqueles que já carregam uma bagagem de conteúdos teóricos e práticos das atividades do projeto, contribuindo para uma personalidade ativa daqueles alunos mais introspectivos, promovendo a socialização com os colegas e com o meio onde está inserido. (SANTOS ET AL, 2016, p. 5).

\footnotetext{
${ }^{4}$ http://www-periodicos-capes-gov-

br.ezl.periodicos.capes.gov.br/index. php?option $=$ com pmetabusca\& $m n=88 \& s m n=88 \&$ type $=m \& m e t a l i b=a H R 0$ cHM6Ly9ybnAtcHJpbW8uaG9zdGVkLmV4bGlicmlzZ3JvdXAuY29tL3ByaW1vX2xpYnJhenkvbGlid2ViL2FjdGlvbi9zZ WFyY2guZG8\%2FZHNjbnQ9MCZwYOF2YWIsYWJpbHR5TW9kZT1mYWxzZSZmcmJnPSZzY3Auc2Nwcz1wcmltb19j ZW50cmFsX211bHRpcGxIX2ZIJnRhYj1kZWZhdWx0X3RhYiZjdD1zZWFyY2gmbW9kZT1CYXNpYyZkdW09dHJ1ZSZp bmR4PTEmZm49c2VhcmNoJnZpZD1DQVBFU19WMQ\%3D\%3D\&buscaRapidaTermo=m\%C3\%BAsica+e+projeto+ social Acesso em: 03/02/2021
}

SOARES, Isac Costa. Aulas de trompete virtuais em meio à pandemia da covid-19 no projeto orquestra jovem do Rio Grande do Sul: um relato de experiência. Revista da FUNDARTE. Montenegro, p.01-16, ano 21, o 44, janeiro/março de 2021.

Disponível em: http://.seer.fundarte.rs.gov.br/index.php/revistadafundarte/index> 30 de março de 2021. 


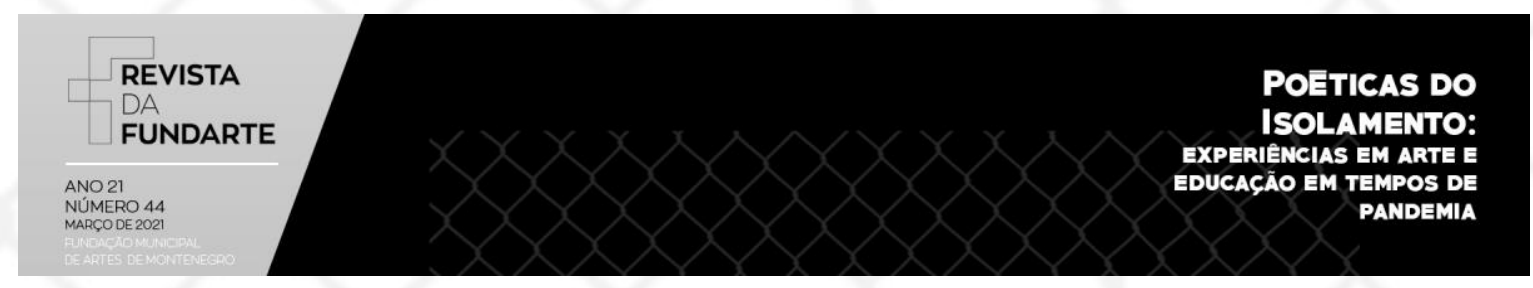

Esses aspectos apontados por Santos et al. (2016) demonstram que o ambiente de ensino de orquestra pode vir a contribuir de forma positiva para a formação de indivíduos, fazendo com que, além do aprendizado musical, haja também desenvolvimento humano.

\section{Sobre a Orquestra Jovem do Rio Grande do Sul}

A Orquestra Jovem do Rio Grande do Sul nasceu no ano de 2009, idealizada pelo maestro Telmo Jaconi ${ }^{5}$ e está situada no bairro cidade baixa na Fundação Pão dos Pobres na cidade de Porto Alegre/RS. O projeto funciona através da captação de recursos via lei de incentivo a cultura e doações. Entre o publico alvo estão crianças e jovens de 10 a 24 anos de idade que tenham baixa renda familiar e que estejam frequentando a escola de ensino regular. Para ingressar, é feito um teste de aptidão musical organizado por uma banca de professores e, a partir dessa seleção os alunos são direcionados para instrumentos de acordo com seus interesses. Atualmente o projeto conta com vinte professores e as aulas e ensaios com a orquestra e grupos de câmara acontecem no período da tarde. Dentre as aulas de instrumentos oferecidos estão: violino, viola, violoncelo, contrabaixo, flauta transversal, oboé, fagote, clarinete, trompete, trompa, trombone, tuba, teclado eletrônico, percussão, flauta doce e teoria musical. Após esse processo e ao ingressar no projeto, o aluno recebe empréstimo do instrumento durante o tempo em que permanecer na orquestra.

Antes da pandemia da Covid-19 as aulas ocorriam em formato presencial uma ou duas vezes por semana, dependendo da demanda de alunos para cada professor, com uma hora de duração. Além disso, havia prática de orquestra, banda

\footnotetext{
5 Telmo Jaconi é natural de Montenegro, mas cresceu em Porto Alegre, onde começou a fazer aula de violino aos 8 anos de idade. Aos 14 anos foi o mais jovem músico admitido pela OSPA, onde permaneceu durante 44 anos, dos quais mais de 30 foi Spalla (violinista principal). Fonte: http://orquestrajovemrs.com.br/ Acesso: 03/01/2021
}

SOARES, Isac Costa. Aulas de trompete virtuais em meio à pandemia da covid-19 no projeto orquestra jovem do Rio Grande do Sul: um relato de experiência. Revista da FUNDARTE. Montenegro, p.01-16, ano 21, o 44, janeiro/março de 2021.

Disponível em: http://.seer.fundarte.rs.gov.br/index.php/revistadafundarte/index> 30 de março de 2021. 


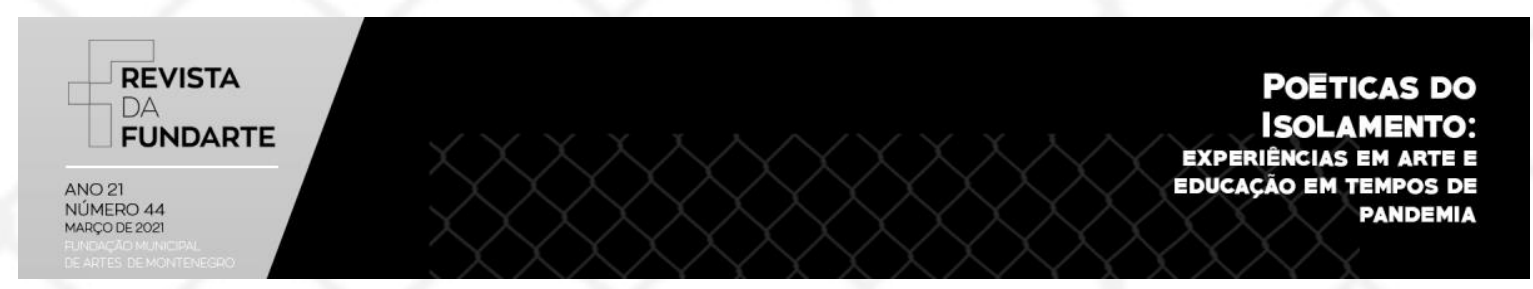

sinfônica para os naipes de metais e madeiras e grupos de câmara. Os ensaios com a orquestra aconteciam todos os dias das $14 \mathrm{~h}$ ás $17 \mathrm{~h} 20$, sendo dividida em dois grupos, orquestra "A" com alunos considerados avançados e intermediários e orquestra "B" com alunos considerados iniciantes. Ademais, havia apresentação dos grupos e concertos com a orquestra em diversos lugares da cidade e estado. Essas experiências em grupo eram muito importantes, contribuíam para relações de afeto e socialização. Souza (2014) explica que:

As experiências em grupo deverão colaborar para a construção do social, das interações e do acolhimento que estabelecem vínculos e promovem o cuidado. Para crianças e adolescentes que são traumatizados, que não têm família ou que não tiveram uma boa socialização primária, a socialização secundária por meio da música pode contribuir para uma reconstituição do tecido social. Nesse âmbito, envolvimento é um conceito importante que está conectado à inclusão e ao ensino/aprendizagem em projetos sociais. (SOUZA, 2014, p. 21).

As experiências vivenciadas em ensaios, concertos e viagens, refletiam no fazer musical em grupo de forma positiva. Era comum ouvir pelos corredores alunos colocando que se sentiam parte de uma família.

O projeto Orquestra Jovem do Rio Grande do Sul tem parceria com o Jovem Aprendiz. Esse programa tem o objetivo de fornecer aos participantes um primeiro contato com o mundo do trabalho ${ }^{6}$. Os alunos matriculados recebem uma bolsa auxílio e passagens. Dessa maneira, conseguem manter-se por mais tempo dentro da Orquestra, não precisando se desvincular para trabalhar em outras áreas.

${ }^{6}$ Fonte: https://www2.portoalegre.rs.gov.br/eptc/default.php?p secao=1698 Acesso em: 03/02/2021

SOARES, Isac Costa. Aulas de trompete virtuais em meio à pandemia da covid-19 no projeto orquestra jovem do Rio Grande do Sul: um relato de experiência. Revista da FUNDARTE. Montenegro, p.01-16, ano 21, o 44, janeiro/março de 2021.

Disponível em: http://.seer.fundarte.rs.gov.br/index.php/revistadafundarte/index> 30 de março de 2021. 


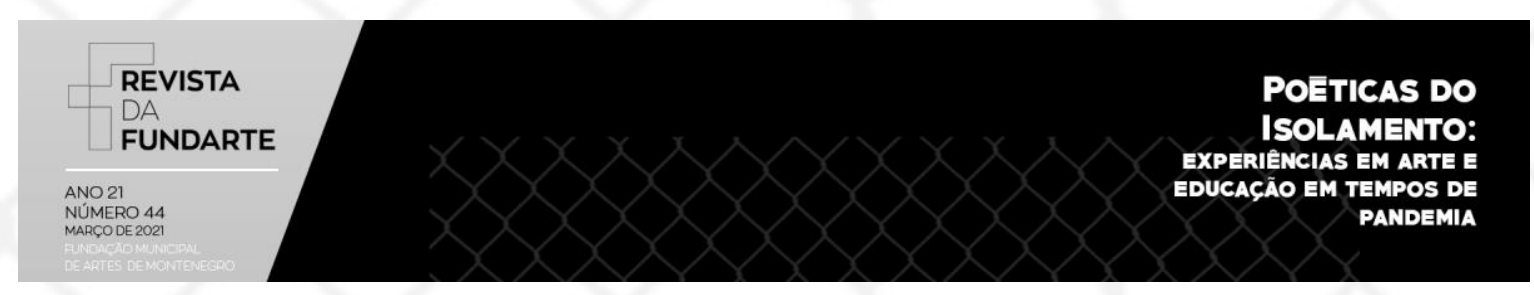

\section{Atividades na Orquestra Jovem do Rio Grande do Sul durante tempos pandêmicos}

No dia 11 março de 2020 é declarado pela organização mundial da saúde a pandemia do novo Coronavírus ${ }^{7}$. Nesse mesmo período, estávamos iniciando as aulas na Orquestra Jovem do Rio Grande do Sul. No entanto, no dia 13 de março, a prefeitura de Porto Alegre lança um decreto suspendendo as atividades de ensino de estabelecimentos públicos e privados ${ }^{8}$. Com isso, o projeto precisou parar e, na mesma semana o professorado foi convocado para uma reunião. A partir disso, ficou estabelecido que os professores dessem continuidade às aulas de forma remota, utilizando a plataforma que melhor funcionasse para os objetivos de cada um.

$\mathrm{Na}$ semana seguinte aconteceu outra reunião, e nela foi colocado que a coordenação estava pensando em um plano de ação para manter o projeto e a Orquestra ativa, pois naquele momento 0 trabalho com 0 grande grupo estava totalmente parado e apenas as atividades de ensino estavam sendo mantidas. Sendo assim, os professores relatavam estar conseguindo manter as aulas através de vídeo chamadas pelo celular, entretanto muitos alunos tinham problemas de conexão e alguns não tinham celulares, tendo que muitas vezes utilizar smartphones de familiares.

Era notável a preocupação da coordenação em fazer a orquestra funcionar de alguma forma para que o trabalho seguisse tendo visibilidade. Surge então a ideia de fazer dois vídeos em formato mosaico com os alunos mais avançados. Espíndola (2020, p. 26) explica que, "para que os alunos possam participar da construção dos vídeos mosaicos, a utilização do aparelho celular se mostra como uma opção segura por manter o isolamento e, dentro das possibilidades, minimamente inclusivas". As músicas escolhidas para os vídeos foram Guantanamera e Cielito lindo. Os dois

\footnotetext{
${ }^{7}$ Fonte: https://www.ufrgs.br/coronaviruslitoral/uma-breve-linha-do-tempo/ Acesso em: 03/02/2021 ${ }^{8}$ Fonte: http://dopaonlineupload.procempa.com.br/dopaonlineupload/3270 ce 284967 1.pdf Acesso em: 03/02/2021
}

SOARES, Isac Costa. Aulas de trompete virtuais em meio à pandemia da covid-19 no projeto orquestra jovem do Rio Grande do Sul: um relato de experiência. Revista da FUNDARTE. Montenegro, p.01-16, ano 21, o 44, janeiro/março de 2021.

Disponível em: http://.seer.fundarte.rs.gov.br/index.php/revistadafundarte/index> 30 de março de 2021. 


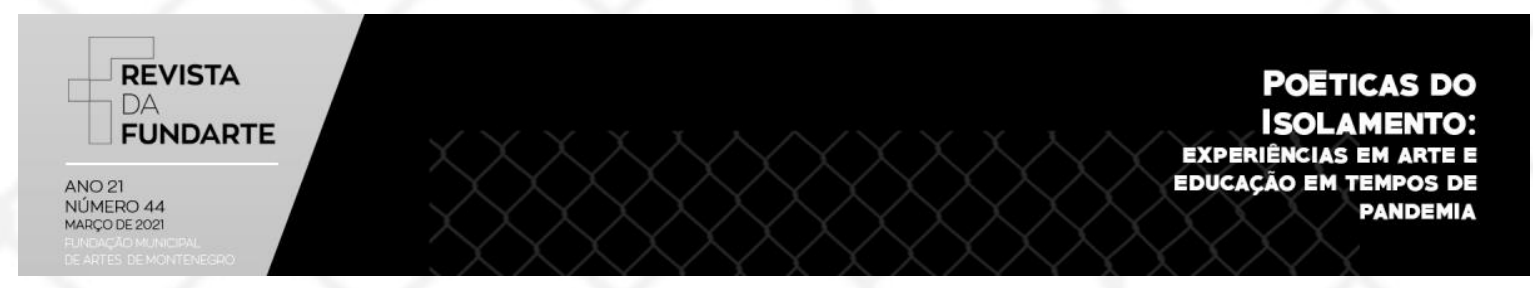

trabalhos foram postados nas redes sociais e no canal do Youtube do projeto. A partir dessa primeira ação, a coordenação percebeu que esse seria o canal de comunicação com o público e a forma de manter visível o trabalho. Sendo assim, novas ações começaram a ser pensadas.

Para uma segunda proposta, pensou-se em produzir uma live ${ }^{9}$ contando a história dos instrumentos de sopro que compõem uma orquestra sinfônica. Para isso, a coordenação organizou o evento em parceria com um estúdio que oferecia o serviço de transmissão online e gravação de áudio e vídeo. Dessa maneira, cada professor foi convidado para falar sobre seu instrumento, junto com um aluno avançado. Além disso, o estúdio possuía um espaço adequado, pois, foi possível fazer o distanciamento sem perder a qualidade da gravação. Esse trabalho recebeu o nome de "Evolução Sinfônica" e foi apresentando no Facebook e posteriormente mantido no canal do Youtube da orquestra.

No terceiro momento, a orquestra começou a produzir lives com músicos convidados para falar sobre suas trajetórias e carreiras. Foi solicitado aos professores que estimulassem a participação dos alunos, pois o número de acesso contaria nos relatórios de prestação de contas do projeto. Essas lives contaram com músicos de renomes do cenário musical gaúcho, tais como, Olinda Allessandrini, Ney Fialkow, Anne Schneider, entre outros, além de músicos do cenário nacional. Considerei essa experiência bem interessante para os alunos, em razão de naquele período com todas as dificuldades que estávamos vivendo a coordenação pensar em uma atividade utilizando as redes sociais na tentativa de manter os alunos próximos.

Como ultima atividade, o projeto começou a fazer lives com os alunos, para as quais foram organizados grupos de câmara com os naipes de metais, madeiras, cordas e percussão. Para as apresentações com transmissão online, foi dado o

\footnotetext{
${ }^{9} \mathrm{https}: / /$ www.techtudo.com.br/noticias/2020/03/o-que-e-uma-live-saiba-tudo-sobre-as-transmissoesao-vivo-na-internet.ghtml Acesso em: 05/02/2021
}

SOARES, Isac Costa. Aulas de trompete virtuais em meio à pandemia da covid-19 no projeto orquestra jovem do Rio Grande do Sul: um relato de experiência. Revista da FUNDARTE. Montenegro, p.01-16, ano 21, oํ 44, janeiro/março de 2021.

Disponível em: http://.seer.fundarte.rs.gov.br/index.php/revistadafundarte/index> 30 de março de 2021. 


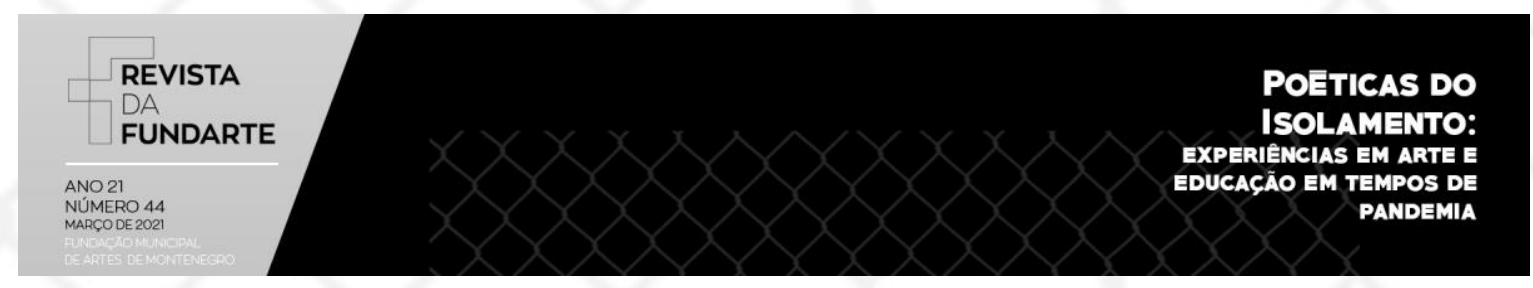

nome de "Concerto Virtual Temporada 2020". Como sou professor de trompete fiquei responsável, junto ao professor de trombone/tuba e trompa, em ajustar dias para os ensaios e repertório. Nesse caso, foi um processo interessante, pois, especificamente, nesse grupo temos alunos com idade a partir dos 17 anos, e as propostas de músicas acabaram partindo deles, sendo tudo organizado via WhatsApp, antes de nos encontrarmos pessoalmente. Para os ensaios o projeto conseguiu uma sala com álcool em gel disponível e bastante espaço, além do uso obrigatório de máscaras.

O primeiro concerto dessa temporada contou com um grupo de cordas composto por professores e alunos do projeto. Entre as obras apresentadas estavam composições de Felix Mendelssohn, Astor Piazzolla e Johannes Brahms. Após esse concerto o projeto seguiu organizando mais seis edições, finalizando com uma apresentação de natal. Todas aconteceram com transmissão ao vivo e contou com equipe de filmagem a captação de áudio.

Além de todas essas ações a orquestra manteve suas páginas nas redes sociais ativas fazendo publicações de "Tbts"10 e divulgações das atividades semanalmente. Como consequência desse esforço mutuo, tanto dos professores, como da coordenação, no final do ano conseguiram mais um patrocínio, o que contribui para manter o projeto no ano de 2021, além de passar a sensação de que todo o esforço valeu a pena.

Por ultimo, ressalto que todas as atividades do projeto estão disponíveis nas redes sociais e canal do Youtube, mostrando que esses espaços tiveram uma grande força em meio à pandemia para quem trabalha com arte, pois foi ali, o meio de comunicação com o público e divulgação dos trabalhos.

\footnotetext{
10 Significado da sigla "tbt": https://www.educamaisbrasil.com.br/educacao/dicas/o-que-significa-tbt Acesso em: 05/02/2021
}

SOARES, Isac Costa. Aulas de trompete virtuais em meio à pandemia da covid-19 no projeto orquestra jovem do Rio Grande do Sul: um relato de experiência. Revista da FUNDARTE. Montenegro, p.01-16, ano 21, oํ 44, janeiro/março de 2021.

Disponível em: http://.seer.fundarte.rs.gov.br/index.php/revistadafundarte/index> 30 de março de 2021. 


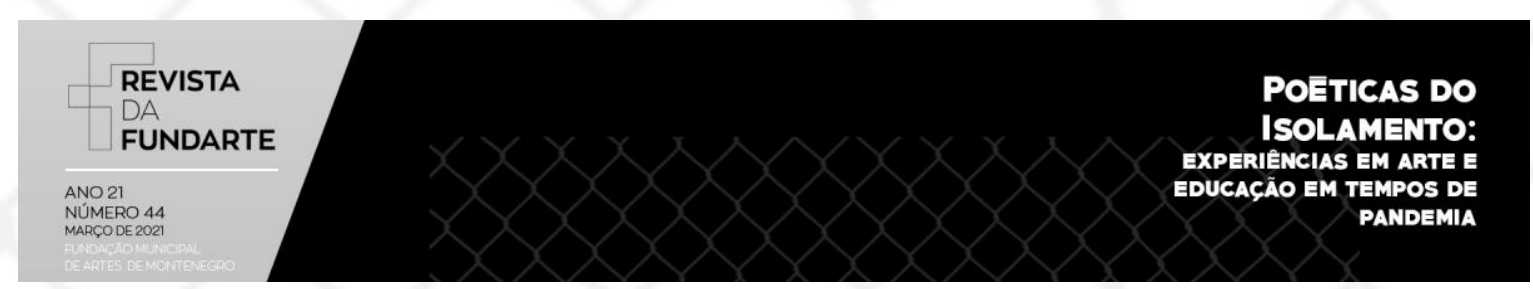

\section{Sobre as aulas de trompete}

Antes da pandemia, as aulas de trompete no projeto, normalmente, eram individuais, tendo um horário estipulado para cada aluno, e aconteciam de forma presencial. Nas aulas eram atendidos cinco alunos de idades entre 16 a 21 anos. A partir das adaptações que tive que fazer com a proposta de começarmos a trabalhar de forma remota, foi necessário conversar com os alunos para compreender a situação em que cada um se encontrava, e qual seria a plataforma que utilizaríamos. A proposta inicial era fazermos aulas através de vídeo chamadas. Como sabia da realidade dos alunos, a primeira ideia que tive foi utilizarmos os smarthphones. Espíndola (2020) coloca que:

Para que seja possível uma aula por videoconferência adequada, parte do pressuposto que o aluno tenha na sua residência itens básicos como conexão de internet e um computador, o que nem sempre é uma realidade. O aparelho celular acaba sendo, na maioria das vezes, uma última opção na busca da interação remota com alunos de baixo poder aquisitivo, quando o tem. Por conta disso, cada aluno manifesta diferentes necessidades que requerem variadas soluções, nem sempre logradoras de êxito, mas valorizadas em cada desfecho positivo. (ESPÍNDOLA, 2020, p. 23).

Sobre as necessidades dos alunos, a partir das conversas que tivemos, percebi que o aplicativo de mais fácil acesso para todos e que consumiria menos dados seria o WhatsApp.

As aulas começaram a ocorrer de forma síncrona, através de vídeo chamada e $o$ atendimento era individual. As aulas presenciais, normalmente duravam em torno de uma hora, no entanto, nesse novo formato de ensino remoto, resolvi adaptar para trinta minutos. Como muitas mudanças estavam ocorrendo, tanto em minha vida como na dos alunos, achei que o melhor seria exigir menos e tentar fazer com que esse momento fosse o mais agradável possível. Todos estavam se adaptando, e alguns chegaram a passar por situações bem complexas, como por exemplo, uma aluna que teve que mudar de casa com sua família, pois sua mãe,

SOARES, Isac Costa. Aulas de trompete virtuais em meio à pandemia da covid-19 no projeto orquestra jovem do Rio Grande do Sul: um relato de experiência. Revista da FUNDARTE. Montenegro, p.01-16, ano 21, o 44, janeiro/março de 2021.

Disponível em: http://.seer.fundarte.rs.gov.br/index.php/revistadafundarte/index> 30 de março de 2021. 


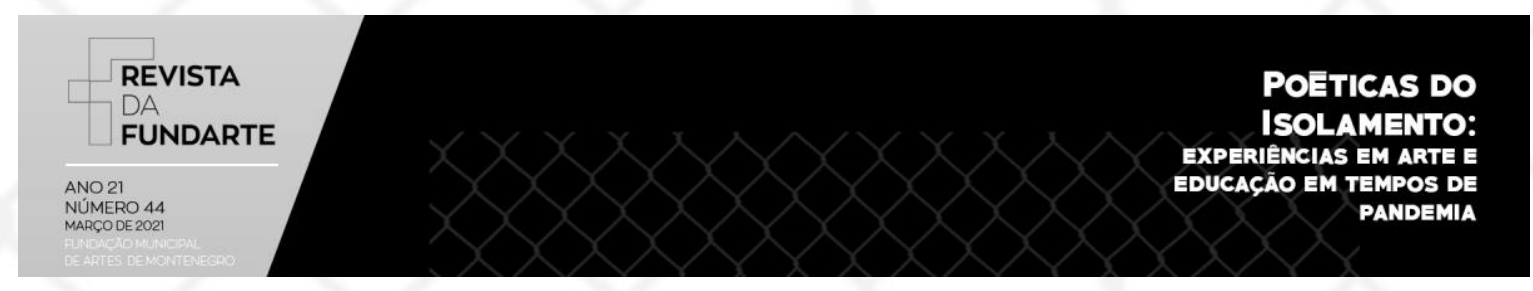

que fazia parte do grupo de risco, estava passando por uma separação com seu cônjuge. Outra aluna buscou ajuda psicológica, relatando que começou a se sentir deprimida e sem expectativa de futuro. Ainda tiveram os que tinham problemas de estímulo, muitas vezes colocando que não sentiam vontade de tocar o instrumento, ou que tinham problemas de organização para estudar e sentiam-se cansados, devido a mudanças na rotina. Todos esses casos acabaram repercutindo nos momentos das aulas, fazendo com que minhas exigências em relação à performance deles não fossem o foco naquela ocasião.

Como ainda era tudo novo para mim, o material que utilizava era o mesmo das aulas presenciais, onde os alunos tinham uma apostila com uma rotina de estudos, organizada compilando os exercícios extraídos de métodos que faziam parte da minha formação como trompetista. Além dessa rotina, exigia também estudos técnicos do método Arban's e estudos melódicos do método Concone, ambos os livros são tradicionalmente utilizados no ensino de trompete. Dessa maneira, os estudos dos alunos eram iniciados pela rotina, depois por estudos técnicos do Arban's e por último, estudos melódicos do Concone. Durante as aulas, a cada semana eles tinham que apresentar algum desses materiais e muitas vezes eles conseguiam mostrar até mais do que era solicitado. Porém, nas aulas síncronas via WhatsApp, notei nas primeiras semanas que eles estavam bem desestimulados e poucos conseguiam apresentar os conteúdos exigidos.

A cada semana de aula notava que os alunos apresentavam mais dificuldades de manter o foco, muitos relatavam dormir até tarde e ter problemas para estudar em casa, devido estarem com toda a família no mesmo espaço. Com isso, começaram a ocorrer faltas. A coordenação do projeto demonstrava preocupação com a presença dos alunos e em mantê-los aptos para tocar. Sendo assim, nas reuniões foi solicitado que intensificássemos nossas falas em relação à presença nas aulas. Além disso, havia alunos que estavam com problemas de

SOARES, Isac Costa. Aulas de trompete virtuais em meio à pandemia da covid-19 no projeto orquestra jovem do Rio Grande do Sul: um relato de experiência. Revista da FUNDARTE. Montenegro, p.01-16, ano 21, no 44, janeiro/março de 2021.

Disponível em: http://.seer.fundarte.rs.gov.br/index.php/revistadafundarte/index> 30 de março de 2021. 


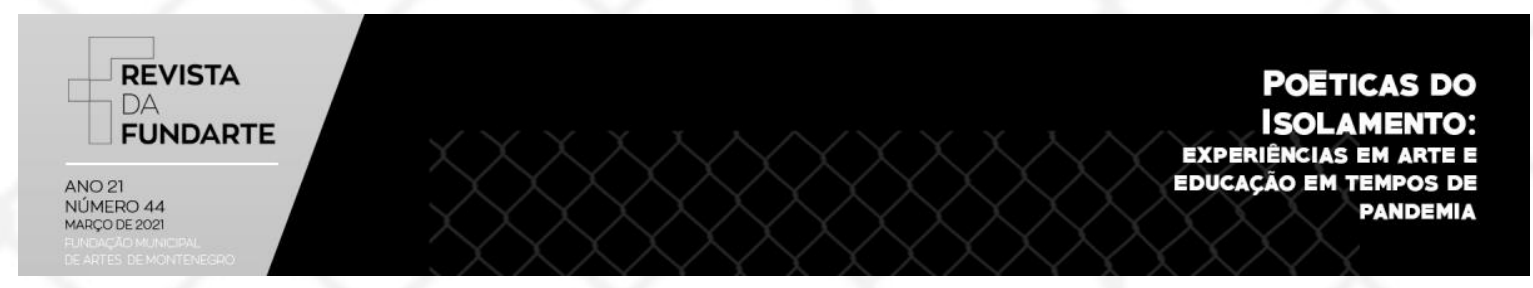

acesso à internet. Para resolver esse dilema foi feito um mapeamento que levou em torno de um mês, para providenciar internet para todos que não tinham condições.

Mesmo com esses percalços sempre tentava estimulá-los, mostrando o quanto estavam melhorando. Kater (2004, p. 45) coloca que, "normalmente o educador musical possibilita ao aluno o contato com suas próprias potencialidades e limites do ponto de vista musical, dando subsídios e orientando sua exploração e superação". Nesse sentido, percebia que era minha obrigação fazer com que os alunos tivessem vontade de seguir estudando. Como exemplo disso, após uma aluna ter relatado estar sem motivação para estudar, propus que ela tirasse de ouvido, ou, que estudasse alguma música que tinha desejo de tocar, sem necessidade de apresentar os estudos que eram solicitados semanalmente.

Com o passar do tempo, os alunos foram se adaptando. Tiveram muitos momentos em aula que notei a importância de manter esse contato com eles. Alguns diziam que ao estudar trompete sentiam que era o melhor momento do dia. Houve também um menino que procurou a orquestra no meio da pandemia querendo fazer aulas de trompete, pois conhecia o professor de fagote que frequentava a mesma igreja, e este professor sempre falava do projeto. Neste caso, foi interessante iniciar aulas de forma online para uma pessoa que nunca tinha visto e nem tido contato pessoalmente. Essa experiência me marcou, e com certeza foi algo inesperado naquele momento.

\section{Conclusão}

Percebi que trabalhar de forma remota em um projeto social é um desafio complexo, uma vez que sabemos que atendem em sua maioria pessoas que estão em situação de vulnerabilidade e que muitas vezes não têm condições de ter acesso à internet e aparelhos que possam comportar plataformas ou aplicativos para aulas online. Sendo assim, esses projetos ficam com a responsabilidade de se organizar

SOARES, Isac Costa. Aulas de trompete virtuais em meio à pandemia da covid-19 no projeto orquestra jovem do Rio Grande do Sul: um relato de experiência. Revista da FUNDARTE. Montenegro, p.01-16, ano 21, no 44, janeiro/março de 2021.

Disponível em: http://.seer.fundarte.rs.gov.br/index.php/revistadafundarte/index> 30 de março de 2021. 


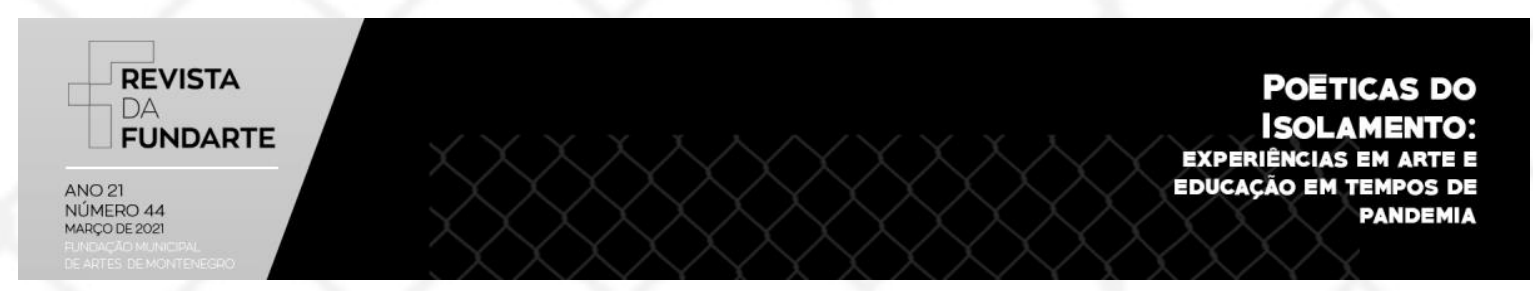

através de apoiadores e doações para conseguir manter as aulas da melhor forma possível e não perderem patrocinadores para manter as instituições. Acredito que esse deveria ser o papel do Estado em um momento difícil como esse, mas sabemos que no Brasil e no atual cenário político esperar por isso seria inocência da nossa parte.

Para finalizar, vejo que muitos foram os aprendizados e desafios que tive como professor nessa imersão de uma "vida" por trás da câmera do celular. Sinto que esse espaço de ensino remoto seguirá existindo, e nós professores teremos que desenvolver cada vez mais habilidades com as ferramentas dos meios digitais, nos adaptando para poder sobreviver em um mundo onde as coisas estão cada vez mais aceleradas, pois tudo está em constante mudança. Bauman (2013, p. 22) explicando o mundo atual que vivemos, o qual ele chama de "mundo líquido", coloca que:

A vida líquido-moderna é uma encenação diária da transitoriedade universal. O que os cidadãos do mundo líquido-moderno logo descobrem é que nada nesse mundo se destina a durar, que dirá para sempre. Objetos hoje recomendados como úteis e indispensáveis tendem a "virar coisa do passado" muito antes de terem tempo de se estabelecer e se transformar em necessidade ou hábito. Nada é visto como estando aqui para sempre, nada parece insubstituível. Tudo nasce com a marca da morte iminente e emerge da linha de produção com o "prazo de validade" impresso ou presumido.

Compreender que estamos vivendo em tempos líquidos nos torna mais hábeis para tomar decisões sensatas. Nesse caso, pode-se dizer que o projeto sobreviveu à pandemia mantendo-se firme e buscando ações alternativas em meio ao caos que nos assolou durante os últimos tempos.

SOARES, Isac Costa. Aulas de trompete virtuais em meio à pandemia da covid-19 no projeto orquestra jovem do Rio Grande do Sul: um relato de experiência. Revista da FUNDARTE. Montenegro, p.01-16, ano 21, o 44, janeiro/março de 2021.

Disponível em: http://.seer.fundarte.rs.gov.br/index.php/revistadafundarte/index> 30 de março de 2021. 


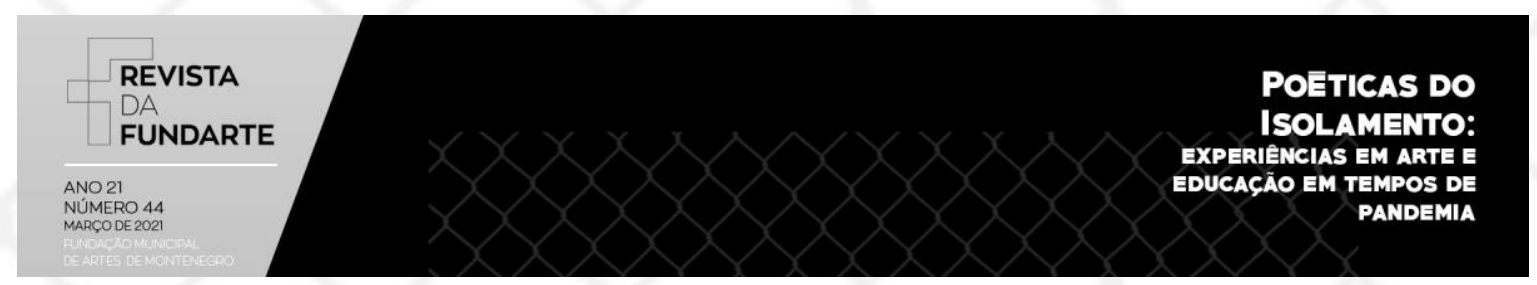

\section{Referencias:}

BAUMAN, Zygmunt. Sobre Educação e Juventude: conversas com Riccardo Mazzeo/Zygmunt Bauman; tradução Carlos Alberto Medeiros. - Rio de Janeiro: Zahar, 2013.

BOZZETO, Adriana. Projetos educativos de famílias e formação musical de crianças e jovens em uma orquestra. Porto Alegre, UFRGS, 2012. Tese (Doutorado em Música). Programa de Pós-Graduação em música, instituto de Artes, Universidade Federal do Rio Grande do Sul, Porto Alegre, 2012.

ESPÍNDOLA, Thiego. Educação Musical em período de isolamento social: um panorama do ensino remoto na escola de música de Biguaçu, Reduzino Romão de Faria. Anais - Encontro de Pesquisa e Extensão do Grupo Música e Educação MusE, v. 1, n. 12020.

KATER, Carlos. O que podemos esperar da educação musical em projetos de ação social. Revista da ABEM, Porto Alegre, V. 10, 43-51, mar. 2004.

SANTOS, Jorge, SANTOS, Paloma, SANTOS, Párbata. Orquestra-Escola: Ensino Coletivo e Inclusão Social no Projeto Orquestra Sinfônica Vale do Cotinguiba. Encontro Internacional de Formação de Professores e Fórum Permanente de Inovação Educacional. V. 9 N. 1, 2016.

SOUZA, Jusamara. Música, educação e projetos sociais. / Jusamara Souza e outros. Porto Alegre: Tomo Editorial, 2014.

TRAMONTE, Cristina, GRUBISIC, Katarina. Educação Musical na Orquestra Escola: Interculturalidade e Prática social em Santa Catarina - orchestral school: Music education and social practice. Revista Pedagógica - UNOCHAPECÓ - Ano - 15 n. 28 vol. 01 - jan/jun, 2012.

SOARES, Isac Costa. Aulas de trompete virtuais em meio à pandemia da covid-19 no projeto orquestra jovem do Rio Grande do Sul: um relato de experiência. Revista da FUNDARTE. Montenegro, p.01-16, ano 21, no 44, janeiro/março de 2021.

Disponível em: http://.seer.fundarte.rs.gov.br/index.php/revistadafundarte/index> 30 de março de 2021. 